\title{
GENETIC ANALYSIS IN CARP (CYPRINUS CARPIO) USING GYNOGENESIS
}

\author{
A. NAGY, K. RAJKI, J. BAKOS* and V. CSANYI \\ Laboratory of Behaviour Genetics, L. Eötvös University, 2131 Göd, Hungary; \\ *Fisheries Research Institute, H-5541 Szarvas, P.O.B. 47, Hungary
}

Received 14.iii.79

\section{Summary}

The present paper reports the utilisation of gynogenesis in genetic analysis and chromosome mapping in carp. A new colour mutant was analysed with the help of gynogenetic haploid, diploid and biparental $F_{1}$ and $F_{2}$ populations. The mutant character was controlled by two genes, $P$ and $R$, and only fish with double recessive alleles pprr showed the mutant coloration. The genekinetochore $(\mathrm{G}-\mathrm{K})$ distances of the genes were established. $\mathrm{G}-\mathrm{K}$ distances were measured for two other genes--transferrin and scaliness.

\section{INTRODUGTION}

GyNOGENESis is the production of an embryo from an egg after penetration by a spermatozoan that does not contribute genetic material. Artificial gynogenesis was first observed in the frog by Hertwig in 1911, who showed that normal embryos appeared when eggs were fertilised by spermatozoa which had received ionising radiation doses much higher than the levels normally required to cause total lethality. The genetic analysis of these embryos showed total maternal genetic contribution.

Gynogenesis has been widely used in different genetic experiments, in studies of karyotypes (Parmenter, 1925, 1933; Kawamura, 1939; Svärdson, 1945), for chromosome mapping (Nace et al., 1970; Volpe, 1970; Purdom, et al., 1976), for establishing inbred strains (Nace, 1968; Purdom, 1969; Stanley and Sneed, 1973; Nagy et al., 1978), and in studies of mutagenesis (Metzger-Freed, 1972).

In most of these studies amphibians were used. The intensive work on fish started in the last decade (Romashov and Belyaeva, 1965; Golovinskaja, 1968; Purdom, 1969; Stanley and Sneed, 1973; Cherfas, 1975).

A reliable method for mass gynogenesis was described for carp in our previous work (Nagy et al., 1978). The present paper reports the utilisation of gynogenesis in the genetic analysis and chromosome mapping of a new colour mutant, the locus controlling transferrin, and the $S$ locus responsible for scale pattern (Kirpichnikov, 1937).

\section{Materials AND methods}

In 1969 a new colour mutant appeared in a Hungarian carp population. The mutant progeny lacked melanophores at 1 month of age, and adults had melanosomes in reduced number. The fish were pale red in colour, but the retinal pigment cells were normal. The $\mathrm{S}$ locus determines the 
scattered and scaly phenotypes (Kirpichnikov, 1937). The scattered allele $(s)$ is completely recessive to the scaled allele $(S)$. In the transferrin locus three different alleles were found in Hungarian carp populations (Nagy et al., 1978), each being represented by a single electrophoretic band.

\section{(i) Detection of phenotypes}

At the time of hatching, the colour mutant embryos are pale pink and have no pigment except in the retina. The separation of the mutant type is possible from the late embryo stage. The frequencies of scattered and scaled phenotypes were established when the animals were more than 1 month old, when their body weights were at least $0.5 \mathrm{~g}$. For transferrin, blood samples were taken from 3-month-old animals. One part of serum was added to 2.4 parts $(v: v)$ of 0.4 per cent rivanol (2-ethoxy-6, 9-diamino acridinlactate) solution to remove most of the proteins other than transferrin. The procedures for electrophoretic separation of proteins were according to Davis (1964).

\section{(ii) Experimental populations}

All the experimental populations originated from a pair of grandparents carrying alleles of the three characteristics in homozygous form. Parents for test populations were chosen from the $F_{1}$ generation (fig. 1).

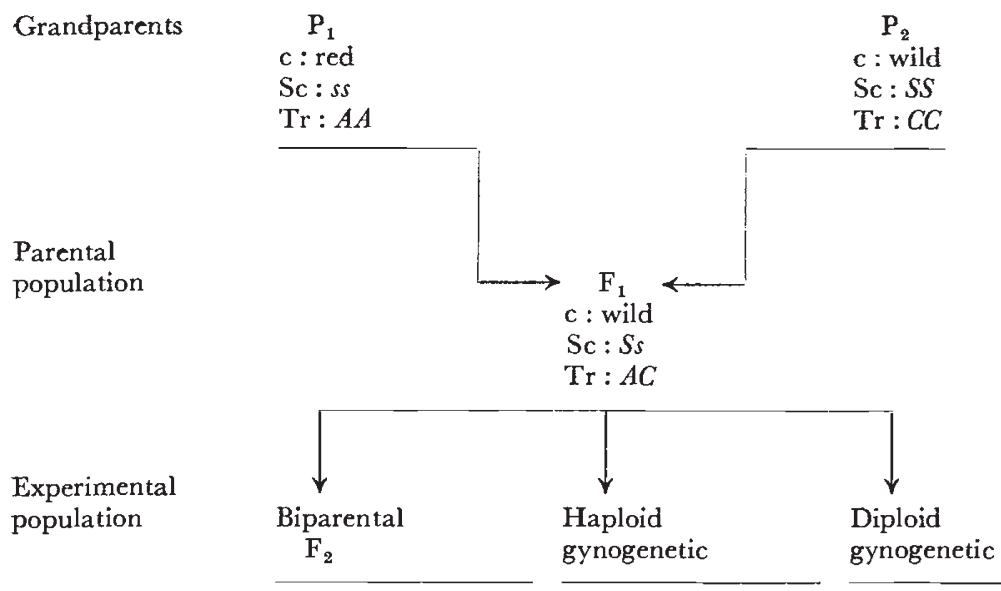

FIG. 1. - The origin of experimental populations $(c=$ phenotype of colour, $\mathrm{Sc}=$ genotype of scale covering, $\operatorname{Tr}=$ genotype of transferrin).

The biparental population was produced by the standard method of artificial insemination (Woynarovich, 1962). The haploid gynogenetic population was produced by insemination with sperm treated with 100 Krad $\gamma$ ray. This treatment produces 99 per cent of haploid embryos (Golovinskaja, 1968). Mass production of diploid gynogenetic embryos was achieve by cooling zygotes quickly to $4^{\circ} \mathrm{C} 5$ and 15 minutes after the insemination by the irradiated sperm. The duration of the cold period was 60 minutes, after which the temperature was allowed to rise to $20^{\circ} \mathrm{C}$. 
(iii) Mapping function

The mapping function used was derived by Barratt et al. (1954) and applied in a closed form to facilitate computation in the work of Nace et al. (1970). From the coefficients of coincidence the two extreme values were used $(k=1.0$ and $0 \cdot 2)$. The lower value was chosen from data. derived from Neurospora crassa and Drosophila melanogaster (Barratt et al., 1954).

\section{Results}

The data and segregation of the colour mutant are given in table 1 . The frequency of mutant embryos in the haploid and the diploid $\mathrm{F}_{2}$ populations were $122: 440=1: 3.6$ and $41: 637=1: 15 \cdot 5$ respectively. The frequencies are consistent with the hypothesis that the mutant characteristic is controlled by two genes.

TABLE 1

Frequencies of red colour mutant and the fit to the model

\begin{tabular}{|c|c|c|c|c|c|}
\hline \multirow[b]{2}{*}{ Population } & \multicolumn{2}{|c|}{ Number of mutants } & \multirow[b]{2}{*}{$n$} & \multirow{2}{*}{$\begin{array}{c}\text { Observed } \\
\text { ratio }\end{array}$} & \\
\hline & Observed & Expected & & & $\chi^{2}$ \\
\hline $\begin{array}{l}\text { Haploid } \\
\text { Biparental }\end{array}$ & $\begin{array}{r}122 \\
41\end{array}$ & $\begin{array}{l}110 \\
39 \cdot 8\end{array}$ & $\begin{array}{l}440 \\
637\end{array}$ & $\begin{array}{l}1: 3 \cdot 6 \\
1: 15 \cdot 5\end{array}$ & \\
\hline
\end{tabular}

It is proposed that the mutant phenotype is pprr. In estimating map distances we assume that there is no difference between the viabilities of the different genotypes. Heterozygous genotypes can appear in diploid gynogenetic populations if recombination occurs between the centromere and the locus. The symbols $Y_{P}$ and $Y_{R}$ are proposed for the probabilities of recombination of the two loci controlling the mutant phenotype. Thus the probability of homozygosity of recessive alleles in both loci in a diploid gynogenetic offspring is given by the equation:

$$
P(\text { mutant })=\frac{1}{4}\left(1-Y_{P}\right)\left(1-Y_{R}\right)
$$

The frequency of mutant type was obtained as $295: 1534=0 \cdot 192$, thus from (1) we get

$$
\left(1-Y_{P}\right)\left(1-Y_{R}\right)=0.768
$$

The value of $Y_{P}$ reaches its maximum when $Y_{R}=\mathrm{O}$ and vice versa. The possible maximum value for $Y_{P}$ or $Y_{R}$ is therefore 0.232 .

The frequency of heterozygotes at the $S$ locus is given in table 2 . In the biparental population, the expected ratio of the scaled to scattered phenotype was $3: 1$ but in our experience the scattered animals show lower viability than the scaled ones. Taking the viability of scaled phenotypes to be one, the viability of scattered animals was estimated by the ratio of the observed and expected frequency in biparental populations. The observed frequency in the diploid gynogentic population was corrected by the help of this coefficient. If the probability of recombination between 
TABLE 2

Observed and corrected frequency of scattered phenotype and corrected values

\begin{tabular}{|c|c|c|c|c|c|c|}
\hline \multirow[b]{2}{*}{ Population } & \multicolumn{3}{|c|}{ Numbers of scattered phenotype } & \multirow[b]{2}{*}{$n$} & \multirow[b]{2}{*}{$n$ cor } & \multirow{2}{*}{$\frac{\text { cor }}{n \text { cor }}$} \\
\hline & Observed & Expected & Corrected & & & \\
\hline Biparental & 59 & $67 \cdot 3$ & - & 261 & - & - \\
\hline Diploid gynogenetic & 142 & - & 162 & 344 & 364 & 0.45 \\
\hline
\end{tabular}

the $\mathrm{S}$ locus and the centromere is $Y_{S}$ the expected frequency of the ss genotype in the diploid gynogenetic population is

$$
\frac{1}{2}\left(1-Y_{S}\right)
$$

From the corrected value of this frequency (table 2)

$$
Y_{S}=0 \cdot 11
$$

In contrast with the characteristics described above, the frequencies of all the three genotypes at the transferrin locus can be established (table 3).

TABLE 3

\begin{tabular}{|c|c|c|c|c|c|c|}
\hline \multirow[b]{2}{*}{ Population } & \multicolumn{3}{|c|}{ Numbers of transferrin genotypes } & \multicolumn{3}{|c|}{ Relative frequencies } \\
\hline & $A A$ & $A C$ & $C C$ & $A A$ & $A C$ & $C C$ \\
\hline $\begin{array}{l}\text { Biparental } \\
\text { Diploid gynogenetic }\end{array}$ & $\begin{array}{l}30 \\
93\end{array}$ & $\begin{array}{l}46 \\
28\end{array}$ & $\begin{array}{l}20 \\
53\end{array}$ & $\begin{array}{l}0.31 \\
0.53\end{array}$ & $\begin{array}{l}0 \cdot 48 \\
0 \cdot 16\end{array}$ & $\begin{array}{l}0.21 \\
0.31\end{array}$ \\
\hline
\end{tabular}

Frequencies of transferrin genotypes in the biparental and diploid gynogenetic population

The expected frequencies of the homozygotes $A A$ and $C C$ are equal. The differences obtained in the experiment may be attributed to the difference in the viabilities of the $A A$ and $C C$ genotypes. Following a correction for this the frequency of gynogenetic heterozygotes gives a recombination estimate

$$
Y_{T r}=0.13
$$

The genes controlling the three characteristics segregated independently in the biparental and diploid gynogenetic populations. On the basis of recombination frequencies individual G-K distances were established (table 4).

\section{TABLE 4}

Recombination frequencies of the four loci examined and the $G-K$ distances

\begin{tabular}{lcccc} 
Gene & $\begin{array}{l}\text { Frequencies of } \\
\text { recombination }\end{array}$ & \multicolumn{1}{c}{$\mathrm{G}-\mathrm{K}$ distances } \\
Red mutant $R$ and $P$ & $0 \geqq r \geqq 0.23$ & & \\
mean value & 0.12 & 0.061 & 0.066 \\
Scaly & $S$ & 0.11 & 0.056 & 0.060 \\
Transferrin & $T_{r}$ & 0.13 & 0.066 & 0.072
\end{tabular}




\section{Discussion}

Haploids may be used to analyse the genetics of characters recognisable at the embryo stage since most of the haploid gynogenetic carp embryos are viable up to hatching (Nagy et al., 1978). A genetic model has been proposed for the red colour mutant following the analysis of haploid gynogenetic and diploid $\mathrm{F}_{2}$ progeny. The mutant appears to be controlled by two genes.

There are a number of species among the Cyprinidae showing a duplicated number of chromosomes compared to the value characterising the family. The phenomenon was interpreted as an ancestral polyploidisation (Ohno and Atkin, 1966; Ohno et al., 1967; Wolf et al., 1969; Ohno, 1970). As a consequence it may be expected that the genetic system contains large numbers of gene duplicates (Kajishima, 1977). It is possible that the colour mutant described here represents such a pair of genes.

Recombination frequency of the $S$ locus of scale covering was measured by Golovinskaja (1968). Among the 61 gynogenetic offspring of the $S S$ genotype there were 18 scattered (ss) individuals. The recombination frequency was determined as $r_{\varepsilon}=0.42$. This surprisingly high value may be the result of the fact that viability differences of the genotypes were not taken into consideration.

Recombination frequency for the transferrin locus was measured by Nagy et al. (1978). In these experiments, a second gynogenetic generation was produced from a gynogenetic female heterozygous at its transferrin locus. The measured recombination frequency was significantly lower than the present level of $0 \cdot 13$. The difference may indicate genotype dependent crossover rate, or the presence of linked genes, with alleles being deleterious in the homozygous state in the normal female used in the second experiment. In a gynogenetic female many of the genes are in the homozygous state, so the effect of deleterious linked genes will be less marked here than when a normal female is used. All four measured recombination frequencies are about $0 \cdot 1$. These low values mean that gynogenesis is a very effective method for producing inbred lines. Using the calculation of Nace et al. (1970) and supposing that the average recombination frequency is about $0 \cdot 1$, one gynogenetic generation is equal to $10-12$ generations of sib-matings with respect to the degree of inbreeding.

\section{REFERENCES}

BARRATT, R. W., NEYMEYER, D., PERKINS, D. D., AND GARNJOBST, L. 1954. Map construction in Neurospora crassa. Adv. Genet., 6, 1-93.

CHERFAs, N. B. 1975. Investigation of radiation induced diploid gynogenesis in the carp (Cyprinus carpio L.). I. Experiments on obtaining the diploid gynogenetic progeny in mass-quantities. Genetika, $9(7), 78-86$ (in Russian).

DAvis, B. J. 1964. Disc electrophoresis. 2. Method and application to human serum proteins. Ann. N.Y. Acad., 121, 305-351.

Golovinskaja, K. A. 1968. Genetics and selections of fish and artificial gynogenesis of the carp (Cyprinus carpio). FAO Fish. Rep. No. 44, Vol. 4, Proc. World Symp. on Warm Water Pond Fish Culture, Rome, 1966. T. V. R. Pillay, ed., pp. 215-222.

hertwig, o. 1911. Die Radiumkrankheit tierischer Keimzellen. Arch. Mikr. Anat., 77, $1-97$.

RAJisHima, T. 1977. Genetic and developmental analysis of some new colour mutants in the goldfish, Carrasius auratus. Genetics, 86, 161-174. 
кAWAmura, т. 1939. Artificial parthenogenesis in the frog. I. Chromosome numbers and their relation to clearage histories. F. Sci. Hiroshima Univ., Ser. B17, 39.

KirPICHNIKov, v. s. 1937. Principal genes of scale in carp. Biol. Zh., 6, 601-632.

METZGER-FREED, L. 1972. Effect of ploidy and mutagens on bromodeoxyuridine resistance in haploid and diploid frog cells. Nature, New Biology, 235, 245-247.

NACE, G. W. 1968. The amphibian facility of the University of Michigan. BioScience, $18,767-775$.

NACE, G. W., RIChards, C. M., AND ASher, J. H. JR. 1970. Parthenogenesis and genetic variability. I. Linkage and inbreeding estimations in the frogs, Rana pipiens. Genetics, $66,349-368$.

NAGY, A., RAJKI, K., HORVÁTH, L., AND CSÁNYI, v. 1978. Investigation on carp, Cyprinus carpio L. gynogenesis. 7. Fish Biol., 13, 215-224.

онNo, s. 1970. Evolution by Gene Duplication. Springer-Verlag, Berlin.

ohNo, s., AND ATKIN, N. B. 1966. Comparative DNA values and chromosome complements of eight species of fishes. Chromosoma, Berl., 18, 455-466.

ohno, s., muramoto, J., Christian, L., AND ATKin, N. B. 1967. Diploid-tetraploid relationship among old-world members of the fish family Cyprinidae. Chromosoma, Berl., 7, 245-250.

PARMENTER, C. L. 1925. The chromosomes of parthegenetic frogs and tadpoles. 7. Gen. Physiol., 8,1 .

PARMENTER, C. L. 1933. Haploid, diploid, triploid and tetraploid chromosome numbers and their origin in parthegenetically developed larvae and frogs of Rana pipiens and Rana Palustris. 7. Exptl. Zool., 66, 409.

PURDOM, C. E. 1969. Radiation-induced gynogenesis and androgenesis in fish. Heredity, $24,431$.

PURDOM, C. E., THOMPSON, AND DANDO, P. R. 1976. Genetic analysis of enzyme polymorphisms in plaice (Pleuronecyes platessa). Heredity, 37, 193.

ROMASHOV, D. D., AND BELYAEVA, v. N. 1965. Increased yield of diploid gynogenetic loach larvae (Misgurnus fossilis L.) induced by temperature shock. Byul. Mosk. Obs. Ispy. Prir. Biol. Ser., 70, 93-104.

STANLEY, G. J., AND SNEED, K. E. 1973. Artificial gynogenesis and its application in genetics and selective breeding of fishes. Proceedings of the Symposium on the Early Life History of Fish, Oban, Scotland, 1973, pp. 527-536. International Council for the Exploration of the Sea.

sVÄrDson, G. 1945. Clıromosome studies on Salmonidae. Medd. Statens Undersökn.-O. Försöksanst. F. Sötvattensfisket, No. 23, 151.

volpe, E. P. 1970. Chromosome mapping in the leopard frog. Genetics, 64, 11-21.

WOLF, U., RITTER, H., ATKIN, N. B., AND OHNO, s. 1969. Polyploidization in the fish family Cyprinidae, order Cypriniformes. I. DNA content and chromosome sets in various species of Cyprinidae. Humangenetik, 7, 240-244.

woynarovich, E. 1962. Hatching of carp eggs in Zuger-glasses and breeding of carp larvae until an age of 10 days. Bamidgeh, 14, 38-46. 